\title{
Gold binding to blood cells and serum proteins during chrysotherapy
}

\author{
R. J. VAN DE STADT AND B. ABBO-TILSTRA \\ From the Amsterdam Centre for Rheumatic Diseases, Amsterdam, Holland
}

SUMMARY The binding of gold to peripheral erythrocytes and serum protein fractions was studied during chrysotherapy of 1 to 2 years' duration in 43 patients with rheumatoid arthritis. In $45 \%$ of the patients more than $10 \%$ of the gold was found to be strongly bound to blood cells. $5-15 \%$ of the metal is bound to non-albumin protein fractions at serum gold concentrations larger than $2 \mu \mathrm{g} / \mathrm{ml}$. In contrast to the cellular binding of gold the relative binding of gold to non-albumin proteins was inversely proportional to the serum concentrations. Binding to neither blood cells nor to non-albumin protein fractions was found to be correlated with clinical parameters.

Gold salts have been used in the treatment of rheumatoid arthritis (RA) for more than 40 years. Although chrysotherapy has proved to be fairly beneficial in the management of rheumatoid arthritis, controversy still exists on the optimal dosage schedule (Krusius et al., 1970; Freyberg, 1972; Lorber, et al., 1973, 1975; Cats, 1976; Rothermich et al., 1976; Sharp et al., 1977). Most reports indicate a lack of correlation between pharmacological and clinical parameters, including the occurrence of adverse reactions (Krusius et al., 1970; Freyberg, 1972; Gerber et al., 1972; Mascarenhas et al., 1972; Rubinstein and Dietz, 1973; Jessop and Johns, 1973; Lorber, et al., 1973, 1975; Gottlieb et al., 1974; Sharp et al., 1977).

In vitro experiments suggest that most of the gold in the circulation is bound to albumin (Lawrence, 1961; McQueen, and Dykes, 1969; Mascarenhas et al., 1972; Campion et al., 1974; Danpure, 1976; Ward et al., 1977), whereas a minor fraction seems to be bound to immunoglobulins, complement (Lorber et al., 1972; Schultz et al., 1973; Ward et al., 1977), or to low molecular weight materials (Campion et al., 1974; Ward et al., 1977). Almost all of these studies have been performed in vitro. In only one study (Ward et al., 1977) was the gold distribution measured in the blood of patients with rheumatoid arthritis receiving chrysotherapy. In the study presented here the binding of gold to erythrocytes and the distribution of gold among the

Accepted for publication 6 March 1979

Correspondence to Dr R. J. van de Stadt, Reuma Revalidatie Centrum, Dr Jan van Breemenstraat Adm. Helfrichstraat, 1056 AB Amsterdam, W. Holland. serum proteins was studied in relationship to clinical parameters.

\section{Material and methods}

\section{PATIENTS}

Forty-two patients comprising 18 men (age range 22-75 years) and 24 women (age range 22-76 years) with definite or classical rheumatoid arthritis lasting for more than 6 months and fulfilling the criteria of the American Rheumatism Association (Ropes et al., 1959) were admitted. None of the patients had previously received chrysotherapy, corticosteroids, immunosuppressive drugs, or Dpenicillamine. Only medication with nonsteroidal anti-inflammatory drugs was allowed simultaneously with the gold therapy. During the trial all patients received aurothioglucose $(20 \%$ oily suspension, Noury Pharma, Oss) by intramuscular injections according to the following standard schedule: The first week $5 \mathrm{mg}$ twice a week, the second week $10 \mathrm{mg}$ twice a week, the third week $20 \mathrm{mg}$ once, after which the dose was increased to 30,40 , and $50 \mathrm{mg}$ a week subsequently in most of the cases. All patients were followed up for 1 to 2 years in this study.

\section{CLINICAL TESTING PROCEDURES}

Before admission to the trial and subsequently at 3-month intervals a complete physical examination was made of all patients. On each occasion the following parameters were assessed; number of ARA criteria, subjective judgment of clinician and patient, pain, morning stiffness, weariness, grip strength, walking time over 10 metres, circumference of large 
and proximal interphalangeal joints, joint index (Ritchie et al., 1968), number of swollen joints, ability to perform activities of daily life (questionnaire), haemoglobin concentration, percentage serum albumin, and erythrocyte sedimentation rate (ESR). On admission to the trial these parameters were assessed on the following 4-point scale; hardly affected (diminished or enhanced), mildly, moderately, or severely affected. By summation of the scores of these variables a total score was obtained for each patient indicating the overall activity of the disease at onset of therapy. On the basis of this total score 3 patients were classified as mildly affected, 14 as mildly to moderately, 22 as moderately, and 3 as severely.

The response of each parameter after a year of therapy was estimated on a 7-point scale, ranging from markedly improved to markedly deteriorated. A change in the joint index, number of swollen joints, pain, and ESR received a weight of 2. By summation of these scores for each patient a total response score was obtained, ranging from 0 (maximal deterioration) to 102 (maximal improvement). Based on this total response score the clinical response of each patient was classified as (a) improved (69 or more), or (b) no significant change or deteriorated (68 or less).

To test the validity of this kind of evaluation, the total response score was compared with the overall judgment of the clinician and with the joint index score separately. The latter 2 parameters correlated well with the total response score $(\mathrm{r}=0 \cdot 71, \mathrm{P}<0.01$; and $\mathrm{r}=0 \cdot 70, \mathrm{P}<0 \cdot 01$, respectively.)

It should be pointed out that in assessment of the clinical response, the occurrence of adverse reactions was excluded as a parameter from the total response score. Adverse reactions were scored separately; mucocutaneous symptoms were confirmed by a dermatologist. In 22 patients mild adverse reactions were noted (Table 1). Usually therapy was discontinued for 1-3 months. Nine patients developed adverse reactions which were classified as serious (Table 1). In these cases gold therapy was permanently stopped. In no patients did serious bone marrow depression or nephrotic syndrome appear.

Table 1 Occurrence of adverse reactions

\begin{tabular}{lll}
\hline & Mild & More serious \\
\hline Dermatitis & 4 & 5 \\
Stomatitis & 1 & 4 \\
Conjunctivitis & 2 & 1 \\
Itching, rash & 13 & 1 \\
Proteinuria & 2 & -1 \\
Vasculitis & - & 12 (in 9 patients) \\
Total & 22 (in 13 patients) & \\
\hline
\end{tabular}

At the onset of therapy and subsequently once a year radiographs of hands, feet, and afflicted joints were analysed by a roentgenologist. This was done serially. The point scale hardly, mildly, moderately, and severely affected was used to classify the patients radiographically at the onset of therapy. A 7-point scale ranging from markedly improved to markedly deteriorated was applied to estimate the radiographical response to therapy so far as the afflicted joints were concerned.

\section{BLOOD SAMPLING}

Serum and blood samples, with heparin or EDTA as anticoagulant, were obtained from the patients just before they received their next injection of aurothioglucose. After centrifugation of the blood, plasma was carefully separated, and the packed erythrocytes were suspended in Hijmans's washing medium (Steffelaar et al., 1976, 1977). After a second centrifugation the cells were suspended in saline up to the original blood volume. $25 \mu \mathrm{l}$ serum was subjected to electrophoresis on cellulose acetate paper of appropriate thickness immediately after collection. Albumin, $\alpha_{1}, \alpha_{2}, \beta$, and $\gamma$ fractions were cut out and dissolved in $80 \%$ acetic acid $(1.0 \mathrm{mb}$ final volume).

All samples were kept frozen in closed vials ato $-20^{\circ} \mathrm{C}$ until measurement.

\section{GOLD DETERMINATIONS}

Blood, serum, plasma, and erythrocyte samples were diluted 5 times in water. $5 \mu l$ was injected directly into a pyrolytically coated graphite cup contained in a carbon rod atomiser (type 63, Varian) mounted in a Varian type AA-5 atomic absorption spectrophotometer (single channel) equipped with a Par lock-in amplifier type 120, a Biomation transient recorder model 802, and a Varian recorder type A-25.10 $\mu$ l of undiluted electrophoresis fractions was injected directly. Since quantitatively the gold content of the albumin fraction greatly exceeds that of the $\alpha_{1}$ fraction, and occasionally the $\alpha_{1}$ fraction did not separate sharply from the albumin fraction, the gold content of the $\alpha_{1}$ fraction may be overestimated. Therefore the percentage of gold found in the albumin plus $\alpha_{1}$ fractions were calculated. The remainder of the metal was bound to and usually evenly distributed over the $\alpha_{2} \beta$, and $\gamma$ fractions.

Signals were compared with aurothiomalate (Merck, Sharpe and Dohme) standards $(0 \cdot 10,0 \cdot 20$, 0.50 , and $1.00 \mu \mathrm{g} \mathrm{Au} / \mathrm{ml}$ ) in exactly corresponding matrices. Pure nitrogen was employed as sheathing gas, cooling was forced by running tap water (cooling time for the electrodermal part between each sample application was $60 \mathrm{~s}$ ), and the atomiser was 
used in the rampmode with a suitable dry-ashatomise cycle. The gold resonance line at $242 \cdot 8 \mathrm{~nm}$ was used. Interference of nonatomic or spectral nature was estimated with a deuterium lamp and subtracted if necessary. This was always done for the measurement of gold in the serum protein fractions. After every 10 samples a standard was included to monitor the small drift. The standard deviation of the signal responses of standard samples $(0 \cdot 20$ and $1.00 \mu \mathrm{g} \mathrm{Au} / \mathrm{ml}$ ) was $5 \%$ of the mean response. Standards were made in pooled human blood, serum, plasma, erythrocyte suspension, and $80 \%$ acetic acid supplemented with appropriate amounts of cellulose-acetate paper and human serum by addition of aurothiomalate. They were kept frozen at $-20^{\circ} \mathrm{C}$ in small closed vials and used only once.

\section{Results}

\section{CELLULAR GOLD BINDING}

In preliminary investigations it has been found that measuring the gold concentration in EDTA plasma gave unreproducible results, whereas determination in heparin plasma or serum gave good reproducibility. This discrepancy could be completely attributed to unreproducible effects of EDTA in the matrices during the atomisation process. The heparin plasma concentrations of gold did not differ from those in the serum, which indicates that no appreciable quantities of gold were bound to fibrinogen. However, in many patients with rheumatoid arthritis under chrysotherapy the calculated blood levels of gold (the plasma concentration multiplied by (1-haematocrit)) were significantly lower than the concentrations measured directly in the blood. As shown in Fig. 1 the difference could be attributed to gold bound to isolated erythrocytes. We were unable to remove the bound gold from the erythrocytes by repeated washings in media containing $4.5 \%$ bovine serum albumin or in human $A B$ serum, nor in media used for fixation of cells for electron microscopy. In the latter case the metal was not seen in electron micrographs of the blood cells. Attempts to remove the metal from the erythrocytes by incubation in isotonic $0.05 \mathrm{M}$ cysteine,

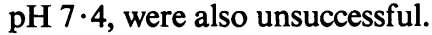

Isolated buffy coat cells also bind comparable quantities of gold. Since the number of white cells is much smaller than the number of red cells the buffy coat cells do not contribute quantitatively to cellular gold binding.

As shown in Fig. 1 cellular gold binding develops from onset of therapy simultaneously with a rise of the gold blood level. After some months of therapy cellular gold binding may vary for individual patients from less than $10 \%$ (arbitrarily assigned as no cellular gold binding) up to $35 \%$ of the gold in the blood. If the blood gold level decreases during therapy, for instance due to interruption of therapy, half of the gold can become bound cellularly (Fig. 1). Binding of gold to erythrocytes is a constant parameter throughout therapy for each individual patient. There was no clear correlation between the blood gold levels (ranging from 0.6 to $3 \cdot 2 \mu \mathrm{g} \mathrm{Au} / \mathrm{ml}$ in 42 patients) and the occurrence of cellular gold binding - that is, more than $10 \%$ of the gold in the blood bound to red cells-which suggests that this property is predominantly determined by the

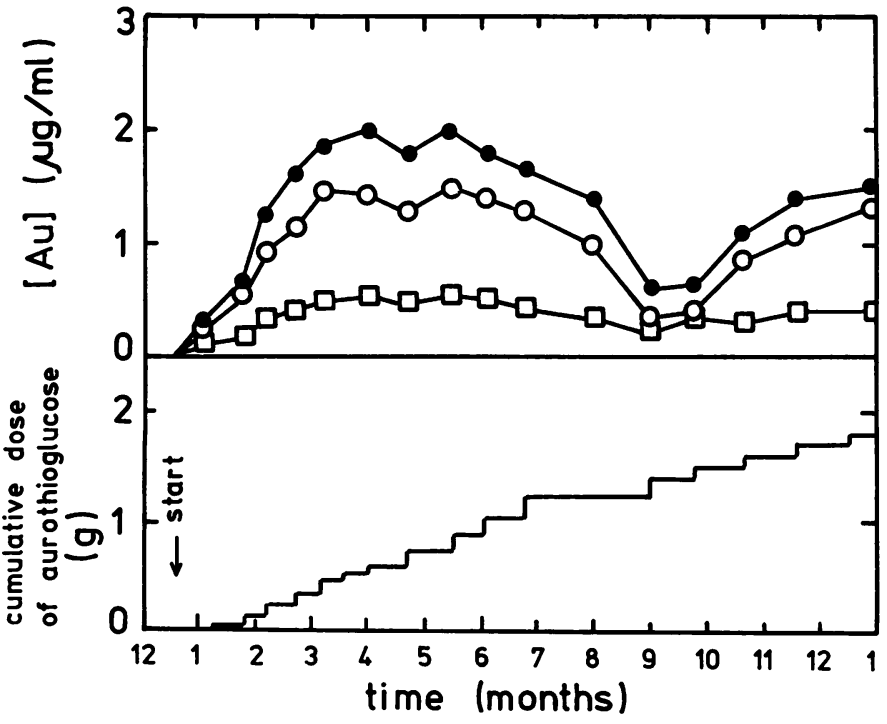

Fig. 1 Cellular gold binding in a patient with rheumatoid arthritis receiving chrysotherapy. - Gold concentration measured directly in the heparinised-blood. O-O Gold concentration in the blood calculated by multiplying the plasma values by (1-haematocrit). $\square-\square$ Gold concentration measured directly in the isolated blood cell suspension. 
erythrocytes. The degree of cellular gold binding was dependent on the blood gold level only at higher blood gold concentrations. For example, Fig. 2 shows results in a patient who received 1000 mg of gold accidentally. Two months elapsed before

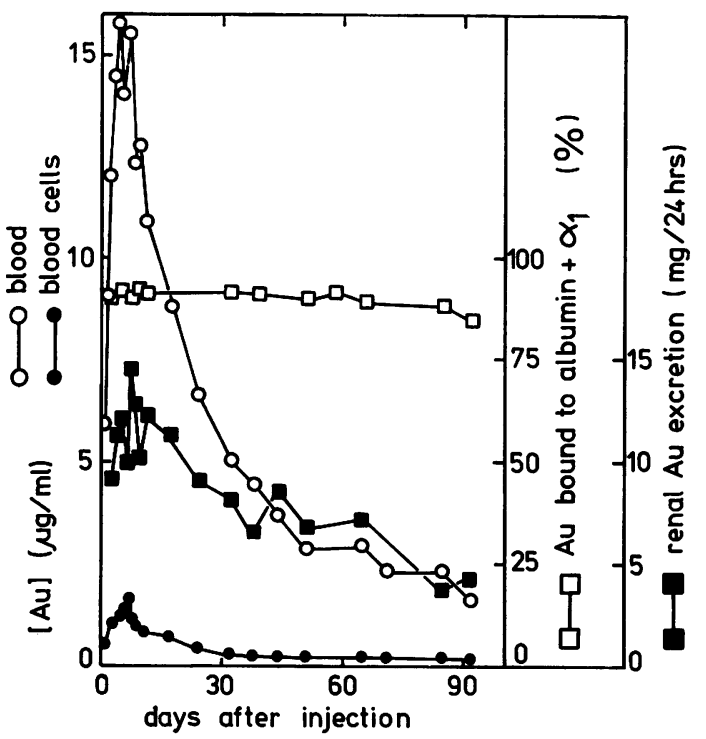

Fig. 2 Gold distribution and renal excretion in a patient with rheumatoid arthritis who by accident received $1000 \mathrm{mg}$ of gold at once. Standard therapy was discontinued for 3 months, during which the patient developed no side effects. After this period mild complaints concerning hair losses and itching soles of the feet were noted for 6 months. the blood level became normal $\left(\mathrm{T}_{\frac{1}{2}}=25\right.$ days). Only at very high gold concentrations in the blood was cellular gold binding induced, but as soon as the blood gold level became normal less than $10 \%$ of the gold was bound cellularly. In this patient the decay in the renal gold excretion was less rapid than that of the blood concentration.

In-vitro incubation of heparinised blood from healthy volunteers with aurothioglucose $(1 \cdot 0,3 \cdot 0$, है and $5.0 \mu \mathrm{g} \mathrm{Au} / \mathrm{ml}$ ) for 10 or $60 \mathrm{~min}$ resulted in cellular binding of gold, the degree of which increased with the gold concentration and the incubation time. There was also a considerable individual variation in the degree of cellular gold binding.

Correlations of cellular gold binding in the patients with other red cell properties such as blood group and rhesus type were lacking.

\section{DISTRIBUTION OF GOLD OVER}

SER UM PROTEINS

At the serum gold concentrations usually reached in standard therapy $85-95 \%$ of the gold is bound to albumin'(Fig. 3). At lower serum gold concentrations the relative proportion of the gold bound to nonalbumin fractions increased significantly $(\mathrm{P}<0.00 \Phi$ for comparison between the percentage bound at 1. and at $2 \cdot 0 \mu \mathrm{g} \mathrm{Au} / \mathrm{ml}$ serum).

\section{CLINICAL RESULTS}

No correlation was found between the clinical and radiographical classification of the patients at onset of therapy. Six patients, however, also showed the main radiographical features of degenerative joint disease. These features were not included in the item

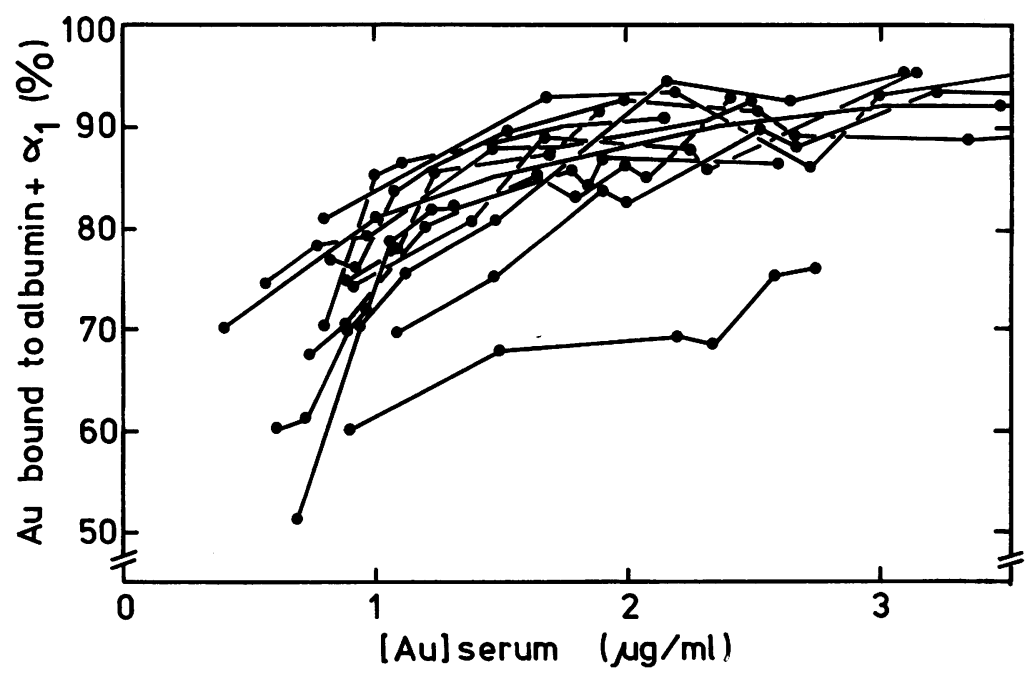

Fig. 3 The relationship between the percentage of gold bound to albumin plus $\alpha_{1}$ and the gold concentration in the serum. Drawn lines give results of at least 5 determinations per patient during their course of therapy. The figure $Q$ gives the results of 12 representative patients. 
list for radiographical evaluation of patients with rheumatoid arthritis. When these 6 patients were omitted a correlation was found between the clinical and radiographical classification of the patients at onset of therapy $(r=0 \cdot 61, P<0 \cdot 01)$.

After 1-2 years of investigation 35 of the 42 ambulant patients $(83 \%)$ were classified as clinically improved so far as the total response score was concerned, 4 patients showed no therapeutic effect, and 3 patients deteriorated slightly. As already mentioned, this classification does not take into account the occurrence of side effects, that is, a patient may improve markedly but still show serious side effects. Radiographically only 2 patients improved slightly, $50 \%$ of the patients remained unchanged, $40 \%$ deteriorated slightly, and 2 patients moderately. Obviously, there was no correlation between the clinical and radiographic results after therapy.

Mild side effects occurred in 13 patients. In 9 other patients therapy was stopped because of more serious adverse reactions occurring after 4-29 months of therapy. It should be pointed out that more serious side effects (Table 1) all occurred in patients who were classified finally as clinically improved. The occurrence of eosinophilia $\left(>0.4 \times 10^{9} / 1\right)$ and assessed once every 3 weeks) and/or raised IgE levels $(>500 \mathrm{IE} / \mathrm{ml}$ and measured once every 3 months) in these patients under chrysotherapy was uncorrelated with manifestations of the side effects listed in Table 1.

\section{GOLD DISTRIBUTION AND CLINICAL \\ RESULTS}

The blood gold levels were correlated neither with therapeutic results (total response score) nor with the occurrence of side effects. The patient who had received $1000 \mathrm{mg}$ of gold (Fig. 2) developed only mild side effects at a time the blood level had already become normal.

Nineteen out of 42 patients ( $45 \%$ ) showed cellular gold binding, in 6 patients only to a minor degree $(10-20 \%)$; in 13 patients more than $20 \%$ of the gold in the blood was bound to erythrocytes. We were unable to establish a relationship between this parameter and the therapeutic results (total response score). Cellular gold binding seemed negatively correlated with the occurrence of more serious side effects $(P=0.08)$. The relationship, however, is not statistically significant. The degree of gold binding to non-albumin protein fractions at serum gold concentrations of 1.0 and $2.0 \mu \mathrm{g} / \mathrm{ml}$ was correlated neither with therapeutic results nor with the occurrence of side effects nor with cellular gold binding in the patients.

\section{Discussion}

In this study it was found that in $45 \%$ of patients with rheumatoid arthritis receiving chrysotherapy an appreciable quantity of the gold in the circulation (up to $35 \%$ ) is bound to blood cells. The metal is not removed from the cells by washing with albumin containing media including human $\mathrm{AB}$ serum, which indicates a strong binding. It has been suggested that aurothiomalate interacts with thiol groups of proteins (Gerber et al., 1974). Interaction of the loaded cells with free thiol groups of cysteine did not release any of the metal from the cells. The bound metal was not detectable under the electron microscope, which suggests a diffuse binding of gold over or in the blood cells. Cellular gold binding proved to be a constant parameter for each patient, predominantly determined by the properties of the patients' blood cells and to a less extent by the blood gold levels, and could be induced in vitro.

In-vitro most of the radioactive labelled gold binds to albumin (McQueen and Dykes, 1969; Mascarenhas et al., 1972; Campion et al., 1974; Danpure, 1976). Ward et al. (1977) measured the plasma gold distribution in vivo in 3 patients with rheumatoid arthritis. They separated albumin from globulin and low molecular weight materials by gel fractionation over Sephadex G-200. At relatively high peak plasma levels $(6-8 \mu \mathrm{g} \mathrm{Au} / \mathrm{ml}) 88-93 \%$ of the gold was bound to albumin, $6-10 \%$ was bound to globulins, and less than $3 \%$ was bound to low molecular weight materials. Our degree of gold binding to albumin at high plasma gold levels in vivo agrees well with the above-mentioned results obtained by different techniques. Ward et al. (1977) did not report the occurrence of unbound metal in vivo as did Campion et al. (1974). The latter group found $10 \%$ 'unbound' metal, that is, metal which passed an ultrafiltration line, in some sera of patients with rheumatoid arthritis receiving gold therapy irrespective of the plasma gold levels. However, the techniques they used are not precisely stated. Our study showed that at lower serum gold levels relatively more gold was bound to non-albumin fractions. The results of this study suggest that the number of binding places for gold on non-albumin protein fractions is small compared to the number of binding places on albumin, whereas the strength of the binding to non-albumin proteins is larger.

None of the available pharmacological parameters of gold metabolism in man are believed to correlate with therapeutic results or the occurrence of side effects. This study shows that 2 new parameters, the cellular binding of gold and the distribution of gold among the serum proteins in vivo, are not correlated with clinical results either. Possibly cellular gold 
binding correlates inversely with the occurrence of serious side effects.

Professor J. K. van der Korst is thanked for his critical reading of the manuscript. The radiographs were scored by P. J. Dijkstra. Fanneke Cnossen did all the typing. The personnel of the clinical chemical laboratory did much of the routine work.

This investigation was supported by financial aid from the Netherlands League against Rheumatism.

\section{References}

Campion, D. S., Olson, R., Bohan, A., and Bluestone, R. (1974). Interaction of gold sodium thiomalate with serum albumin. Journal of Rheumatology, 1, 112.

Cats, A. (1976). A multicentre controlled trial of the effects of different dosage of gold therapy, followed by a maintenance dosage. Agents and Actions, 6, 355-363.

Danpure, C. J. (1976). Interaction of aurothiomalate with human serum albumin in vitro. Biochemical Society Transactions, 4, 161-163.

Freyberg, R. J. (revised by Ziff, M., and Baum, J.) (1972). Gold therapy for rheumatoid arthritis. In Arthritis and Allied Conditions, 8th edn., p. 455. Edited by J. H. Hollander and D. J. McCarthy. Lea and Febiger: Philadelphia.

Gerber, R. C., Paulus, H. E., Bluestone, R., and Pearson, C. M. (1972). Clinical response and gold levels in chrysotherapy: lack of correlation. Annals of the Rheumatic Diseases, 31, 308-310.

Gerber, R. C., Paulus, H. E., Jennrich, R. I., Lederer, M., Bluestone, R., Bladh, W. H., and Pearson, C. M. (1974). Gold kinetics following aurothiomalate therapy: use of a whole body radiation counter. Journal of the Laboratory and Clinical Medicine, 83, 778-789.

Gottlieb, N. L., Smith, P. M., and Smith, E. M. (1974). Pharmacodynamics of ${ }^{197} \mathrm{Au}$ and ${ }^{195} \mathrm{Au}$ labelled aurothiomalate in blood: correlation with course of RA, gold toxicity and gold excretion. Arthritis and Rheumatism, 17, 171-183.

Jessop, J. D., and Johns, R. G. S. (1973). Serum gold determinations in patients with rheumatoid arthritis receiving sodium autothiomalate. Annals of the Rheumatic Diseases, 32, 228-232.

Krusius, F. E., Markkane, A., and Peltota, P. (1970). Plasma levels and urinary excretion of gold during routine treatment of RA. Annals of the Rheumatic Diseases, 29, 232235.

Lawrence, J. S. (1961). Studies with radioactive gold. Annals of the Rheumatic Diseases, 20, 341-361.

Lorber, A., Bovy, R. A., and Chang, C. C. (1972). Relationship between serum gold content and distribution to serum immunologlobulins and complement. Nature New Biclogy, 236, 250-252.

Lorber, A., Atkins, C. J., Chang, C. C., Lee, Y. B., Starrs, J., and Bovy, R. A. (1973). Monitoring serum gold values to improve chrysotherapy in rheumatoid arthritis. Annals of the Rheumatic Diseases, 32, 133-139.

Lorber, A., Simon, T. M., Leeb, J., and Carroll, P. E. (1975) Chrysotherapy: pharmacological and clinical correlates. Journal of Rheumatology, 2, 402-410.

Mascarenhas, B. R., Granda, J. L., and Freyberg, R. H. (1972). Gold metabolism in patients with rheumatoid arthritis treated with gold compounds-reinvestigated Arthritis and Rheumatism, 15, 391-402.

McQueen, E. G., and Dykes, P. W. (1969). The transport of gold in the body. Annals of the Rheumatic Diseases, 28, 437-442.

Ritchie, D. M., Boyle, J. A., McInnes, J. M., Jasani, M. K., Dalakos, T. G., Grieveson, P., and Watson Buchanan, W. (1968). Clinical studies with an articular index for the assessment of joint tenderness in patients with rheumatoid arthritis. Quarterly Journal of Medicine, 37, 393-406.

Ropes, M. W., Bennett, G. A., and Cobb, S. (1959). Diagnostic criteria for rheumatoid arthritis, 1958 revision Annals of the Rheumatic Diseases, 18, 49-53.

Rothermich, N. O., Philips, V. K., Bergen, W., and Thomas, M. H. (1976). Chrysotherapy: a prospective study. Arthritis and Rheumatism, 19, 1321-1327.

Rubinstein, H. M., and Dietz, A. A. (1973). Serum gold. II. Levels in rheumatoid arthritis. Annals of the Rheumatic Diseases, 32, 128-132.

Schultz, D. R., Gottlieb, N L., and Arnold, P. I. (1973) Effects of gold on functional activities of individuat complement components. Arthritis and Rheumatism, 16; 131.

Sharp, J. T., Lidsky, M. D., Duffy, J., Thompson, H. K., Person, B. D., Masri, A. F., and Adrianakos, A. A. (1977). Comparison of two dosage schedules of gold salts in the treatment of rheumatoid arthritis. Arthritis and Rheumatism, 20, 1179-1187.

Steffelaar, J. W., Graaff-Reitsma, Clair, B. de, and FeltkampVroom, T. M. (1976). Immune complex detection by immunofluorescence on peripheral blood leukocytes. Clinic al and Experimental Immunology, 23, 272-278.

Steffelaar, J. W., Kate, F. J. W. ten, Nap, M., Swaak, A. J. G. Graaff-Reitsma, C. B., de, Elfen, E. H. van, and FeltkampVroom, T. M. (1977). Immune complex detection by immunofluorescence on polymorphonuclear leucocytes. Clinical and Experimental Immunology, 27, 391-396.

Ward, R. J., Danpure, C. J., and Fyfe, D. A. (1977). Determination of gold in plasma and plasma fractions by atomic absorption spectrometry and by neutron activation analysis. Clinica Chimica Acta, 81, 87-97. 